Article

\title{
In Vitro Evaluation of Adhesion Capacity, Hydrophobicity, and Auto-Aggregation of Newly Isolated Potential Probiotic Strains
}

\author{
Gabriela Krausova *, Ivana Hyrslova and Iveta Hynstova \\ Department of Microbiology and Technology, Dairy Research Institute, Ltd., Ke Dvoru 12a, 16000 Prague, \\ Czech Republic; ivana.hyrslova@gmail.com (I.H.); ivet.hynstova@gmail.com (I.H.) \\ * Correspondence: krausova@milcom-as.cz or gabika.kunova@gmail.com; Tel.: +420-773-088-810
}

Received: 30 September 2019; Accepted: 2 December 2019; Published: 4 December 2019

\begin{abstract}
We isolated several strains of human and animal origin, focusing on the genera Lactobacillus and Bifidobacterium. Samples of cow colostrum, feces and saliva of calves and piglets, and infant feces were acquired, bacterial strains were isolated and identified, and twenty strains of lactobacilli and bifidobacteria were shortlisted for further in vitro analysis of adhesion capacity to human cells, surface hydrophobicity, and auto-aggregation. Adhesion capacity was evaluated using a mixture of Caco-2 and HT-29-MTX cells and hydrophobicity was measured using the microbial adhesion to the hydrocarbon method. Lactobacillus reuteri was the most frequently isolated species, followed by L. casei subsp. paracasei and L. gasseri; all strains were isolated from infant feces. Bifidobacteria were represented by the species B. longum (infant feces), and B. thermophilum and B. pseudolongum (calves, piglets). All twenty strains showed good adhesion capacities to the mixed cell culture (17.7-37.2\%), particularly, L. reuteri isolates K7 and K14 (37.2\% and 35.5\%, respectively). In hydrophobicity and auto-aggregation assays, strain-specific differences irrespective of the origin or taxonomic group were observed. Hydrophobicity values varied considerably (from $6.1 \%$ to $87.4 \%$ ), whereas auto-aggregation ability ranged from $21.7 \%$ to $69.7 \%$. No relation was observed between hydrophobicity and adhesion capacity; instead, auto-aggregation was apparently related with adhesion.
\end{abstract}

Keywords: adherence; Caco-2; HT-29-MTX; probiotics; auto-aggregation; hydrophobicity

\section{Introduction}

Many probiotic products containing a variety of probiotic microorganisms are available in the market, and they are enjoying increasing popularity. Probiotics are defined as live microorganisms that when administered in adequate amounts confer a health benefit on the host [1]. However, to designate microorganisms as probiotic microorganisms, a number of criteria must be met. The microorganisms must be alive in an adequate number when administered, they must be genetically identified, and designated and classified using the latest terminology [2]. Importantly, probiotics must be tested for their pathogenicity, tolerance to bile and acids present in the gastrointestinal tract, and the ability to adhere to the intestinal mucosa [3]. A large number of bacterial strains, especially from the genera Lactobacillus and Bifidobacterium are currently marketed as probiotics [4]. The representatives of these two genera are the most used probiotics because of their health benefits to humans, as well as animals [5,6]. They have a long history of use and have the generally recognized as safe (GRAS) status. The members of the Bifidobacterium genus comprise a dominant group of human adult intestinal microbiota and represent up to $90 \%$ of the fecal anaerobic strains of the breast-fed infants $[7,8]$. The genus Lactobacillus belongs to a group of lactic acid bacteria (LAB) and includes a variety of species, such as Lactobacillus plantarum, L. fermentum, L. rhamnosus, L. acidophilus, L. reuteri, L. delbrueckii subsp. 
bulgaricus [9]. They are widely found in various ecosystems, especially in foods such as dairy products, fermented vegetables, silage, or fermented beverages. Lactobacilli are one of the most prevalent groups of human-associated bacteria, being a part of the gastrointestinal, respiratory, and genital tracts of humans $[5,10]$.

The ability to adhere to the mucus produced by intestinal epithelium is one of the main criteria for selecting probiotics. Having this ability may increase their chances of survival in the gastrointestinal tract and thus allow bacteria to exert their positive health effects $[6,11]$. Although adhesion capacity of probiotic bacteria does not necessarily ensure a health benefit, their attachment to intestinal epithelium can have a protective role against harmful bacteria via competition for host cell binding sites [12]. Bacterial adherence has been commonly evaluated in vitro using human cell lines to mimic the adhesion of bacteria to epithelial cells or abiotic surfaces. During the last decades, many in vitro studies were conducted to evaluate the adhesion capacity of various bacterial species. In these studies, the Caco-2 and HT-29-MTX cell lines are the most widely used cell lines for the evaluation of adhesion and anti-adhesion properties of bacterial strains. Caco-2 cells lack mucus secretion, whereas HT-29-MTX cells differentiate in vitro into goblet cells producing mucus that is physiologically present in the human gastrointestinal tract. To drive their differentiation in vitro, methotrexate (MTX) is used. The secreted mucus is mainly composed of the MUC5AC mucin, which is produced in the stomach [13,14]. Generally, adhesion is a complex process involving non-specific (hydrophobic interactions between cell surfaces) and specific ligand-receptor interactions [6]. Different structures and specific cell wall components of bacteria, such as fimbriae or pili, adhesins, mucus-binding proteins, fibronectin-binding proteins, or surface layer proteins, provide them an advantage for epithelial colonization; further, lipoteichoic acid or exopolysaccharides produced by bacteria can contribute to adhesion to host epithelial cells $[12,13,15,16]$. Interactions among all these properties important for adhesion provide the benefit of intestine colonization to probiotic strains. Auto-aggregation of probiotic bacteria is necessary for adhesion to epithelial cells and mucosal surfaces, and thus for the colonization of the gastrointestinal tract [17]. Moreover, it is an important phenotype for adhesion [13]. Auto-aggregation appears to be the first step in the adhesion process, allowing bacteria to form a barrier and prevent the adhesion of undesirable bacteria [18]. Cell surface hydrophobicity is another property considered important in overall adhesion capacity. It is most frequently measured by evaluating the affinity of bacteria to a hydrocarbon solvent; for example, the microbial adhesion to hydrocarbon (MATH) method that determines bacterial membrane hydrophobicity or hydrophilic nature of the cell surface. According to a recent study [19], bacteria with higher hydrophobicity can bind better to epithelial cells and thus influencing the adhesion ability to some extent. According to Falah et al. [5], hydrophobicity examination can be considered a pre-test of the adhesion capacity of probiotic bacteria to epithelial cells. They also consider hydrophobicity as one of the important properties improving the first contact between bacteria and host cells. The overall adhesion is a complex process involving more different parameters, e.g., surface exopolysaccharides, S-layer protein, lipoteichoic acid, and others [20]. Auto-aggregation, co-aggregation, and surface hydrophobicity are characteristics that provide potential advantages for microorganisms in colonizing the intestinal tract [20].

We aimed to isolate novel candidate probiotic strains of human and animal origin and to evaluate their probiotic properties, such as adhesion capacity, auto-aggregation, and hydrophobicity using in vitro methods. We isolated 20 strains of lactobacilli and bifidobacteria. In addition to evaluating their probiotic properties, we aimed to evaluate possible associations among these properties.

\section{Materials and Methods}

\subsection{Samples}

To isolate novel probiotic strains, twenty samples of colostrum taken immediately after calving from Red Land cattle breed were used (agricultural farm Kojcice, Czech Republic). Furthermore, twenty-five feces samples were acquired from piglets and calves fed with colostrum. In addition, 
twenty swabs were taken from the muzzles of colostrum-fed calves who were 0-3 days old. To isolate probiotic strains of human origin, 25 feces samples of breast-fed infants aged up to six months were used. Samples were collected into tubes containing Wilkins-Chalgren broth supplemented with $10 \%$ glycerol, and were frozen at $-20^{\circ} \mathrm{C}$.

\subsection{Isolation}

To isolate strains of the genus Bifidobacterium, a medium supplemented with mupirocin and norfloxacin was used, as described previously [21]. To isolate strains of the genus Lactobacillus, de Man, Rogosa, and Sharpe (MRS) agar ( $\mathrm{pH}$ 6.2) supplemented with $0.01 \%$ L-cysteine hydrochloride (Sigma-Aldrich, Czech Rep.) and MRS agar ( $\mathrm{pH}$ 5.7) were used. Bacteria were cultivated under anaerobic conditions at $37^{\circ} \mathrm{C}$ for $48-72 \mathrm{~h}$. Individual colonies were then transferred to MRS agar ( $\mathrm{pH}$ 6.2) supplemented with $0.05 \%$ L-cysteine hydrochloride) or MRS agar (pH 5.7). After microscopic control, strains were three times re-inoculated and finally grown on sheep blood agar. Subsequent identification of the isolates was performed using matrix-assisted laser desorption/ionization assay with the time-of-flight detector (MALDI-TOF, State Veterinary Institute, Jihlava, Czech Republic).

\subsection{Evaluation of Hydrophobicity and Auto-Aggregation}

To determine the hydrophobicity of isolated strains, the MATH method by Vinderola et al. [22] was used, and to determine the auto-aggregation, the method of Zuo et al. [7] was used. In both cases, bacterial suspensions grown overnight in an MRS broth were harvested by centrifugation at $6000 \mathrm{rpm}$ for $8 \mathrm{~min}$ at laboratory temperature. The cells were washed twice using phosphate buffer ( $\mathrm{pH}$ 6.6) and adjusted to the optical density of $0.55-0.60$ at $600 \mathrm{~nm}$ (A0, H0). For the auto-aggregation assay, each bacterial suspension $(8 \mathrm{~mL})$ was incubated at $37^{\circ} \mathrm{C}$ and the auto-aggregation values were measured at 3, 6, and $24 \mathrm{~h}$ (At). To determine the hydrophobicity of the cell surface, hexane was used as a solvent. Hexane was added to the cell suspension and the mixture was vortexed for $1 \mathrm{~min}$. After phase stabilization and separation (10 $\mathrm{min}$, laboratory temperature), the optical density of the aqueous phase was measured at $600 \mathrm{~nm}$ (H1). The values of auto-aggregation and hydrophobicity were calculated according to the following formulae:

$$
\begin{gathered}
\mathrm{A}=\left(1-\mathrm{A}_{\mathrm{t}} / \mathrm{A}_{0}\right) \times 100 \% \\
\mathrm{H}=\left(\mathrm{H}_{0}-\mathrm{H}_{\mathrm{t}}\right) / \mathrm{H}_{0} \times 100 \%
\end{gathered}
$$

\subsection{Adhesion to Caco-2 and HT-29-MTX Cell Lines}

A mixed culture of two cell lines HT-29 (ATCC HTB-38) and Caco-2 (ATCC HTB-39) was used to create a model of intestinal mucosa. The cell line HT-29 was cultivated in Dulbecco's modified eagle medium (DMEM, Lonza) supplemented with 15\% fetal bovine serum (FBS, Sigma-Aldrich), 1\% penicillin/streptomycin (P/S, Lonza), and 1\% sodium pyruvate (Lonza). This culture was differentiated using $10 \mu \mathrm{M}$ methotrexate (MTX) to constantly produce mucin as previously described and modified by Kadlec and Jakubec [23]. Shortly, the cells were incubated with MTX for 14 days without passage until they recovered their division ability. The differentiated cell line was named HT-29-MTX, and it was cultivated in the same media as that of the original culture. The cell line Caco-2 was cultivated in Eagle's minimal essential medium (EMEM, Lonza, Basel Switzerland) supplemented with 20\% FBS (Sigma Aldrich Prague, Czech Republic), 1\% P/S, (Lonza), and 1\% L-glutamine (Lonza). All cell lines were cultivated in $37^{\circ} \mathrm{C}$ and $5 \% \mathrm{CO}_{2}$.

Before the actual experiment, cell lines Caco-2 and HT-29-MTX were mixed in the ratio 9:1 and $2 \times 10^{5}$ cells/well were seeded in a 96-well microtiter plate. The cells were incubated in EMEM until $100 \%$ confluence was achieved (usually $24 \mathrm{~h}$ ).

All tested strains were cultivated for $24 \mathrm{~h}$ in the standard culture broth before the adhesion experiment. Bacterial suspension was then washed twice in physiological saline solution (PS) and 
finally resuspended in PS to an optical density 0.5 measured at $600 \mathrm{~nm}$. This suspension was then fluorescently marked by adding $50 \mu \mathrm{M}$ Syto 9 (Life technologies) and incubating for $1 \mathrm{~h}$ at $37^{\circ} \mathrm{C}$ in the dark. Subsequently, $100 \mu \mathrm{L}$ of the stained bacterial suspension was added to 10 wells of the microtiter plate that had the mixed cell culture. Further, $100 \mu \mathrm{l}$ PS or $100 \mu \mathrm{l}$ of $5 \%$ prebiotic (saccharide) solution was added; the final concentration of the prebiotic solution was thus $2.5 \%$. The plate was incubated for $1 \mathrm{~h}$ at $37^{\circ} \mathrm{C}$ and $5 \% \mathrm{CO}_{2}$ in the dark. Subsequently, half of the wells (5 wells) was used as a control of $100 \%$ fluorescence present in the wells. The rest was washed $2 \times 200 \mu \mathrm{l}$ PS and irrigated with clear suspension of PS or $2.5 \%$ prebiotic or saccharide. Fluorescence was measured at $478 / 510 \mathrm{~nm}$ using the fluorescence reader Synergy 2 (Tecan Männedorf, Switzerland). All experiments were done in triplicate.

Percentage of adhesion was calculated as:

$$
X(\%)=(X R F U-N K) /(P K-N K)
$$

where $X(\%)$ is percentage of fluorescence in the well; $X_{\mathrm{RFU}}=$ well fluorescence in relative fluorescence units; $\mathrm{NK}=$ negative control (nonspecific well fluorescence); $\mathrm{PK}=$ positive control (bacterial fluorescence without wash). For statistical evaluation of the data, Statgraphics ${ }^{\circledR}$ Centurion XV Software (StatPoint, Inc., Warrenton, VA, USA) and the multiple range comparison LSD test were used. A difference was considered to be statistically significant at the level of $p<0.05$.

\section{Results and Discussion}

To isolate novel potential probiotic candidates, samples of cow colostrum, feces and saliva of calves and piglets, as well as feces of infants were used. The most frequently isolated bacterial strains from these samples were representatives of the genus Lactobacillus. Among lactobacilli, the species $L$. reuteri $(29.7 \%)$ was isolated most frequently, followed by L. casei subsp. paracasei $(11.0 \%)$ and L. gasseri (5.5\%). The species L. brevis and L. murinus (both 3.3\%) and L. fermentum (2.2\%) were also found. Approximately $1 \%$ of the isolated lactobacilli was classified according to the database as L. saerimneri, L. amylovorus, L. mucosae, and L. johnsonii. Bifidobacteria were represented by the species Bifidobacterium longum of which two strains were found in infant feces and one in calf saliva. Moreover, B. thermophilum and B. pseudolongum were found in calf and piglet feces. Among lactobacilli, the species L. gasseri, L. fermentum, and L. casei subsp. paracasei were isolated from all types of specimens tested, i.e., infant feces, calf and piglet feces, as well as colostrum. L. reuteri isolates originated in the great majority of infant feces. L. murinus and L. brevis were found only in animal samples (feces of calves and piglets and colostrum). In this work, we focused primarily on the isolation of the two genera Bifidobacterium and Lactobacillus, which are most important as potential probiotic strains. However, on the cultivation media used, species from other genera were also detected; for example, Enterococcus faecium (12.1\%), E. faecalis (8.8\%), and E. durans (1.1\%) from the genus Enterococcus and Klebsiella oxytoca (3.3\%) and Escherichia coli (2.2\%) from the genera Klebsiella and Escherichia, respectively. Although colostrum and milk produced by mammary glands of healthy mammals are considered sterile, bacteria, such as streptococci, staphylococci, and lactic acid bacteria, can get through the teat canal into the udder parenchyma. Therefore, small amounts of microorganisms can be detected even in aseptically collected milk and colostrum [24,25]. Another possible route of transfer of microorganisms into colostrum and milk is via the contact of teats with litter and silage [26].

Some strains were shortlisted from the obtained isolates of lactobacilli and bifidobacteria for further testing (Table 1). 
Table 1. Isolates selected for further testing.

\begin{tabular}{|c|c|c|}
\hline Strain & Origin & Identification \\
\hline$E 4 M A$ & infant feces & L. reuteri \\
\hline$E 2 M D$ & infant feces & L. reuteri \\
\hline E3TA & infant feces & L. casei subsp. paracasei \\
\hline E1M1C & infant feces & L. reuteri \\
\hline$E 3 T D$ & infant feces & L. casei subsp. paracasei \\
\hline E3M2 & infant feces & L. reuteri \\
\hline$Z 1$ & infant feces & L. casei subsp. paracasei \\
\hline Z17 & infant feces & L. casei subsp. paracasei \\
\hline Z9 & infant feces & L. casei subsp. paracasei \\
\hline K18 & cow colostrum & L. reuteri \\
\hline$K 7$ & cow colostrum & L. reuteri \\
\hline K14 & cow colostrum & L. reuteri \\
\hline K10B & cow colostrum & L. brevis \\
\hline$S 3 A$ & feces of piglets & B. pseudolongum \\
\hline$S 4 B$ & feces of piglets & B. thermophilum \\
\hline$T 11 B$ & feces of calves & B. thermophilum \\
\hline$T 12 B$ & feces of calves & B. thermophilum \\
\hline$T 1 C$ & feces of calves & B. thermophilum \\
\hline SL5B & saliva of calves & B. longum \\
\hline TS $1 C$ & saliva of calves & L. reuteri \\
\hline
\end{tabular}

Adhesion to epithelial cells and subsequent colonization of the gastrointestinal tract is a property that confers great advantage to probiotic bacteria and helps them effectively compete and proliferate in the gut. Thus, this is a desirable property to look for while isolating novel probiotic strains. To determine adhesion properties in vitro, cell cultures of Caco-2 cells and mucus-secreting HT-29-MTX colorectal adenocarcinoma cells are the most often used [27]. MATH and auto-aggregation or co-aggregation are more likely supplemental assays to study adhesion properties of bacterial cells. Bacterial adhesion is based on non-specific physicochemical interactions between two surfaces, and therefore, it is usually associated with the characteristics of the cell surface. The adhesion ability to mucin-producing cells is better than to non-mucus-producing ones; thus, the presence of mucus seems to play a major role in adhesion [13]. Accordingly, to compare adhesive properties of bacteria in vitro, we used a co-culture of non-mucus-secreting Caco-2 cells and mucus-secreting HT-29-MTX cells in the ratio 9:1 as a model of intestinal mucosa. Both the cell lines are derived from human colorectal adenocarcinoma cells, which are of intestinal mucosal origin. The intestinal mucosa is characterized by the production of mucin, a slimy glycoprotein that forms a protective layer in the intestine. For better simulation, HT-29 cells were differentiated using MTX to continuously express mucin [14]. The abovementioned human intestinal cell lines have been extensively used in recent studies. The adhesion capacities of selected strains to the Caco-2 and HT-29-MTX mixed cell culture are compared in Figure 1. The adhesion capacity varied considerably among the strains. Overall, all tested strains were able to adhere well to the mixed cell culture under in vitro conditions; their adhesion capacity ranged from 17.7-37.2\%, with L. reuteri strains $\mathrm{K} 7$ and $\mathrm{K} 14$ adhering most efficiently at $37.2 \%$ and $35.5 \%$, respectively. Both these strains were isolated from colostrum. A few strains isolated from infant feces (L. casei subsp. paracasei E3TD and E3TA, L. reuteri E2MD and E3M2) and a new strain isolated from colostrum (L. brevis K10B) also showed adhesion capacity above $30 \%$. On the contrary, B. thermophilum T1C was least efficient, with adhesion capacity of $17.7 \%$. Several past studies have tested probiotic strains for their adhesion capacities; however, their findings are hardly comparable because of differences in tissue models used [28]. Falah et al. [5] reported that the adhesion capacity of L. fermentum, a strain isolated from cereal fermented food, to Caco-2 cells is $8.5 \%$. In this study, however, no mucin-producing cell lines were used. Further, substantial adherence $(40 \%)$ of L. paracasei isolated from kefir grains to HT-29 cell lines was reported by Mantzourani et al. [29]. 


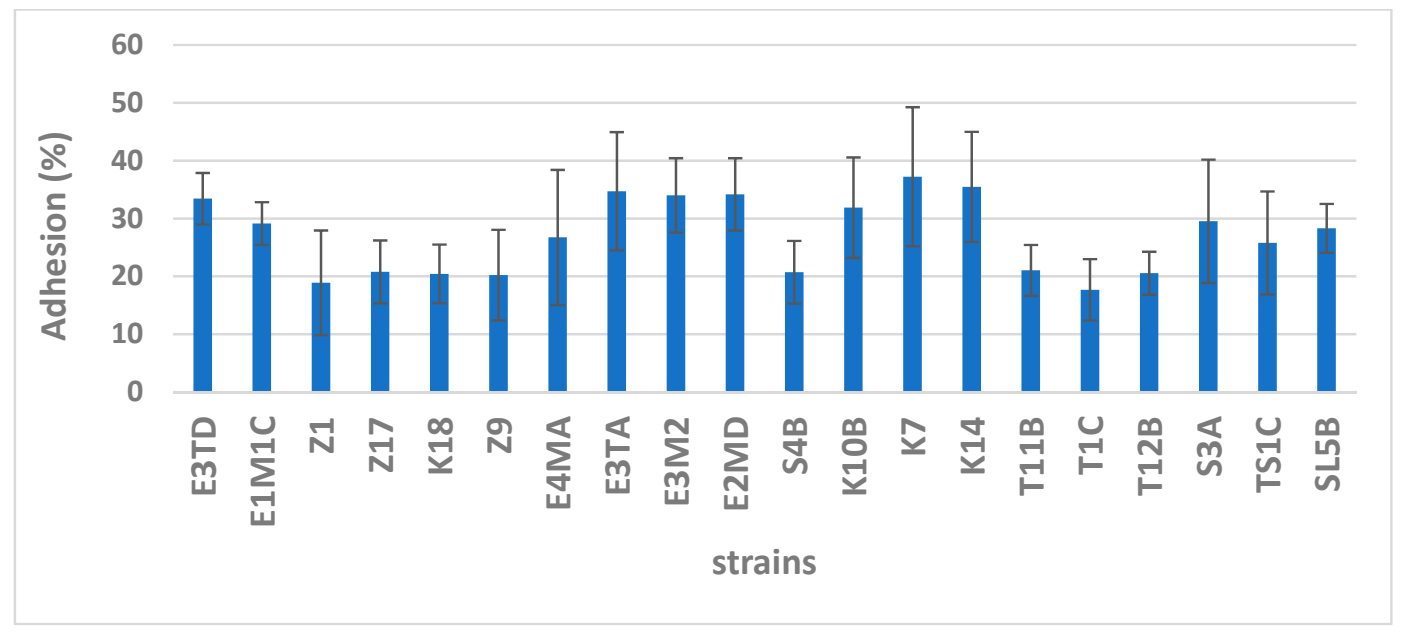

Figure 1. Adhesion assay. Adhesion capacity (\%) of isolated strains to the Caco-2 and HT-29-MTX mixed culture. Bars denote $95 \%$ confidence intervals.

MATH is the most commonly used method for measuring the hydrophobicity of the cell surface of lactic acid bacteria [30]. This method evaluates hydrophobicity as the affinity of microorganisms to a solvent (e.g., hexane, xylene, toluene). In this work, extraction with hexane was used (Table 2). The highest hydrophobicity was determined for the B. thermophilum T11B strain (87.4\%). Furthermore, high hydrophobicity (> 70\%) was detected for the L. reuteri $\mathrm{K} 18(76.0 \%)$ and B. thermophilum S4B $(78.2 \%)$ strains. Past studies have shown that higher hydrophobicity of the cell surface leads to higher adhesion to Caco-2 cells and vice versa [31]. In the strains tested in this study, this hypothesis was not confirmed; on the contrary, an opposite trend was observed. For example, the strain E3M2 of L. reuteri (isolated from infant feces), which is one of the best adhering strains in this study, showed hydrophobicity of just 9.1\%. A similar trend was observed for the strain E3TD (also isolated from infant feces); it showed good adhesion capacity to the cell culture (33.4\%) but had low hydrophobicity $(11.3 \%)$. Overall, isolates of human origin (infant feces) displayed the lowest values of hydrophobicity compared to those of other isolates. In the study by Gomaa et al. [17], the best adhesion capacity was observed when xylene was used as a solvent in all the strains of lactobacilli tested. The highest hydrophobicity values were calculated for L. casei (73.3\%) in the abovementioned study. According to some recent studies, the hydrophobicity levels of 19 strains of $L$. fermentum and L. casei varied from $0.3 \%$ to $68.8 \%$ [19]. Such a great variation in hydrophobicity values is consistent with our observations. The MATH method is considerably sensitive to a number of factors such as cultivation time, composition of cultivation media, presence of some acids, and the type of solvent used. As shown by Wu and Shah [32], hydrophobicity of lactobacilli probably decreases in the presence of elaidic acid. This acid belongs to a group of trans fatty acids responsible for cardiovascular diseases. Further, as presented, it can change the surface physicochemical properties of lactobacilli. Furthermore, the presence and concentration of saccharides in the cultivation medium play a role in determining cell surface hydrophobicity. When lactose is used as a sole carbon source, cell surface hydrophobicity of probiotic strains increases [33]. Addition of prebiotic levan also enhances the hydrophobicity of the probiotic strain L. acidophilus La5. On the contrary, presence of bile salts and hydrochloric acid negatively influence cell surface hydrophobicity [33]. Importantly, the MATH method does not measure the cell surface hydrophobicity itself; instead, it reflects van der Waals and electrostatic forces as important factors interplaying in overall adhesion capacity [34]. The correlation between adhesion and hydrophobicity has been investigated in a number of studies with often contradictory results, because cell adhesion properties are influenced by a variety of factors such as the composition of the culture medium, temperature, and $\mathrm{pH}[11,30,35]$. According to Falah et al. [5], hydrophobicity examination can be considered a pre-test of the adhesion capacity of probiotic bacteria to epithelial cells. They also consider hydrophobicity as one 
of the important properties improving the first contact between bacteria and host cells. Some authors, e.g., [19], consider that bacteria with high hydrophobicity have better ability to bind to epithelial cells.

Table 2. Hydrophobicity (\%) of isolated strains (MATH).

\begin{tabular}{cc}
\hline Strain & Hydrophobicity(\%) \\
\hline L. reuteri E4MA & $7.6 \pm 1.4^{\mathrm{a}, \mathrm{b}}$ \\
L. casei subsp. paracasei E3TD & $11.3 \pm 1.5^{\mathrm{a}, \mathrm{b}, \mathrm{c}, \mathrm{d}}$ \\
L. reuteri E2MD & $8.6^{\mathrm{a}} \pm 0.6^{\mathrm{b}, \mathrm{c}}$ \\
L. reuteri E1M1C & $6.1 \pm 2.4^{\mathrm{a}}$ \\
L. casei subsp. paracasei E3TA & $16.2 \pm 2.4^{\mathrm{b}, \mathrm{c}, \mathrm{d}, \mathrm{e}}$ \\
L. reuteri E3M2 & $9.1 \pm 3.0^{\mathrm{a}, \mathrm{b}, \mathrm{c}}$ \\
L. casei subsp. paracasei Z1 & $52.2 \pm 3.9^{\mathrm{h}}$ \\
L. casei subsp. paracasei Z17 & $60.7 \pm 1.5^{\mathrm{h}, \mathrm{i}}$ \\
L. casei subsp. paracasei Z9 & $52.2 \pm 2.0^{\mathrm{h}}$ \\
L. reuteri K18 & $76.0 \pm 2.5^{\mathrm{j}}$ \\
L. amylovorus K7 & $30.6 \pm 11.2^{\mathrm{f}, \mathrm{g}}$ \\
L. reuteri K14 & $34.3 \pm 9.9^{\mathrm{g}}$ \\
L. reuteri K10B & $37.9 \pm 1.8^{\mathrm{g}}$ \\
B. pseudolongum S3A & $63.4 \pm 4.1^{\mathrm{i}}$ \\
B. thermophilum S4B & $78.2 \pm 10.5^{\mathrm{j}}$ \\
B. thermophilum T11B & $87.4 \pm 1.5^{\mathrm{k}}$ \\
B. thermophilum T12B & $20.4 \pm 0.8^{\mathrm{d}, \mathrm{e}}$ \\
B. thermophilum T1C & $24.6 \pm 1.2^{\mathrm{e}, \mathrm{f}}$ \\
B. longum SL5B & $39.2 \pm 13.5^{\mathrm{g}}$ \\
L. reuteri TS1C & $17.4 \pm 3.5^{\mathrm{c}, \mathrm{d}, \mathrm{e}}$ \\
\hline
\end{tabular}

Data are expressed as \% of auto-aggregation measured after $24 \mathrm{~h}$ of incubation. Values are means of triplicate measurements \pm standard deviation. ${ }^{\mathrm{a}, \mathrm{b}, \mathrm{c}, \mathrm{d}, \mathrm{e}, \mathrm{f}, \mathrm{g}, \mathrm{h}, \mathrm{i}, \mathrm{i}, \mathrm{j}, \mathrm{k}}$ Data in the column with different superscripts differ $(p<0.05)$.

Bacterial auto-aggregation is a process by which bacteria physically interact with each other and settle to the bottom in a static liquid suspension [36]. Capability of bacteria to form cellular aggregates via auto-aggregation (aggregation of bacteria of the same strain) or via co-aggregation (aggregation of bacteria of genetically different strains) can also contribute to persistence in the intestine. Moreover, aggregation can act antagonistically toward potential pathogenic microorganisms [11,37]. The ability of auto-aggregation has been associated with adhesion. To achieve the desired benefit of probiotic bacteria, they need to form a sufficiently large biomass through aggregation. Regarding the significance of co-aggregation, contradictory opinions exist in the literature. According to some researchers, lower levels of co-aggregation with pathogens is required for probiotics to prevent biofilm formation and further minimize pathogen colonization of the gastrointestinal tract [38]. On the contrary, some other researchers have stated that co-aggregation of probiotic bacteria with pathogens is a positive feature, because it is one of the possible ways to eliminate pathogens from the gastrointestinal tract $[19,39]$. In this study, the aggregation ability with genetically different strains (co-aggregation) was not tested; only auto-aggregation was assayed. All the strains tested in this study exhibited some degree of auto-aggregation (Table 3) already from the first time of $3 \mathrm{~h}$ (from $5.8 \%$ to $24.0 \%$ ), which continually increased with time. The highest percentage of auto-aggregation was observed after $24 \mathrm{~h}$, ranging from $21.7 \%$ to $69.7 \%$. Excellent auto-aggregation ability was exhibited by the strains of lactobacilli isolated from colostrum (Table 2). A slightly lower percentage of auto-aggregation was observed in lactobacilli isolated from infant feces and the weakest was observed in isolates obtained from calves and piglets. Based on the literature, obligatory homofermentative lactobacilli, such as L. crispatus, L. acidophilus, and L. gasseri, exhibit higher values of auto-aggregation [40]. In the present study, all tested strains showed high auto-aggregation ability after $24 \mathrm{~h}$ of incubation. A time-dependent increase in this ability was observed. Particularly the strains B. pseudolongum S3A (isolated from piglets) showed auto-aggregation ability of $69.7 \%$ and L. reuteri K18 and K7 (both colostrum) of $66.6 \%$ and $65.4 \%$, respectively. Further, L. brevis K10B (colostrum) showed $64.4 \%$ and L. casei subsp. paracasei Z17 (infant 
feces) showed $63.6 \%$ at the end of incubation ( $24 \mathrm{~h})$. Overall, isolates from colostrum exhibited the best auto-aggregation properties. On the contrary, the strain of animal origin B. thermophilum T12B showed the lowest auto-aggregation ability of $21.7 \%$. For comparison, lactobacilli isolates used in the study by Gomaa et al. [17], exhibited excellent auto-aggregation properties (from $51.12 \%$ to $78.17 \%$ ) already after $5 \mathrm{~h}$ of incubation. In our isolates, such a high percentage of auto-aggregation was observed after a longer time of incubation $(24 \mathrm{~h})$. High auto-aggregation was also reported for the strains of L. casei and L. fermentum, ranging from $60.97 \%$ to $96.18 \%$ [19]. Some studies reported a correlation between aggregation and adhesion capacity [41]; on the contrary, other studies did not demonstrate such a correlation and link between these two properties [13]. According to our results, strains having good adhesion capacities to the cell culture, usually had good auto-aggregation properties. This correlation could have been seen in the case of isolates from colostrum (L. reuteri $\mathrm{K} 7$ and $\mathrm{K} 18$ ) and isolates originating from infant feces (e.g., L. reuteri E3M2 and E2MD).

Table 3. Auto-aggregation (\%) of isolated strains.

\begin{tabular}{|c|c|c|c|c|}
\hline \multirow[b]{2}{*}{ Origin } & \multirow[b]{2}{*}{ Strain } & \multicolumn{3}{|c|}{ Auto-Aggregation (\%) } \\
\hline & & $3 \mathrm{~h}$ & $6 \mathrm{~h}$ & $24 \mathrm{~h}$ \\
\hline \multirow{9}{*}{ Infant feces } & E4MA & $12.8 \pm 3.8^{\mathrm{a}, \mathrm{b}, \mathrm{c}}$ & $19.1 \pm 3.6^{\mathrm{a}, \mathrm{b}, \mathrm{c}, \mathrm{d}}$ & $56.6 \pm 0.6^{\mathrm{e}, \mathrm{f}, \mathrm{g}, \mathrm{h}, \mathrm{i}}$ \\
\hline & E3TD & $7.9 \pm 1.5^{\mathrm{a}, \mathrm{b}, \mathrm{c}}$ & $17.3 \pm 1.3^{a, b, c}$ & $50.6 \pm 2.0^{\mathrm{d}, \mathrm{e}, \mathrm{f}, \mathrm{g}}$ \\
\hline & E2MD & $9.3 \pm 0.9^{a, b, c}$ & $15.9 \pm 2.5^{\mathrm{a}, \mathrm{b}}$ & $50.2 \pm 4.1^{\mathrm{d}, \mathrm{e}, \mathrm{f}, \mathrm{g}}$ \\
\hline & E3TA & $11.7 \pm 1.4^{\mathrm{a}, \mathrm{b}, \mathrm{c}}$ & $18.2 \pm 1.2^{\mathrm{a}, \mathrm{b}, \mathrm{c}}$ & $35.7 \pm 16.1^{\mathrm{a}, \mathrm{b}, \mathrm{c}}$ \\
\hline & E1M1C & $11.3 \pm 1.0^{\mathrm{a}, \mathrm{b}, \mathrm{c}}$ & $17.2 \pm 0.1^{\mathrm{a}, \mathrm{b}, \mathrm{c}}$ & $46.3 \pm 6.3^{c, d, e, f}$ \\
\hline & E3M2 & $6.3 \pm 2.1^{a, b}$ & $16.4 \pm 1.4^{\mathrm{a}, \mathrm{b}, \mathrm{c}}$ & $55.1 \pm 1.7^{\mathrm{e}, \mathrm{f}, \mathrm{g}, \mathrm{h}}$ \\
\hline & Z1 & $6.8 \pm 1.1^{\mathrm{a}, \mathrm{b}}$ & $16.6 \pm 0.9^{a, b, c}$ & $59.0 \pm 13.8^{\mathrm{f}, \mathrm{g}, \mathrm{h}, \mathrm{i}}$ \\
\hline & Z9 & $5.8 \pm 3.8^{\mathrm{a}}$ & $11.6 \pm 0.2^{\mathrm{a}}$ & $57.7 \pm 5.6^{\mathrm{e}, \mathrm{f}, \mathrm{g}, \mathrm{h}, \mathrm{i}}$ \\
\hline & $\mathrm{Z} 17$ & $11.9 \pm 2.2^{\mathrm{a}, \mathrm{b}, \mathrm{c}}$ & $18.4 \pm 6.0^{\mathrm{a}, \mathrm{b}, \mathrm{c}}$ & $63.6 \pm 19.3^{g, h, i}$ \\
\hline \multirow{4}{*}{ Colostrum } & K7 & $14.7 \pm 2.3^{c}$ & $20.9 \pm 3.3^{b, c, d, e}$ & $65.4 \pm 14.2^{\mathrm{h}, \mathrm{i}}$ \\
\hline & K10B & $13.3 \pm 0.4^{\mathrm{a}, \mathrm{b}, \mathrm{c}}$ & $14.4 \pm 11.4^{\mathrm{a}, \mathrm{b}}$ & $64.4 \pm 1.6^{\mathrm{g}, \mathrm{h}, \mathrm{i}}$ \\
\hline & K14 & $9.2 \pm 5.9^{\mathrm{a}, \mathrm{b}, \mathrm{c}}$ & $16.3 \pm 8.6^{\mathrm{a}, \mathrm{b}}$ & $44.4 \pm 4.5^{\mathrm{c}, \mathrm{d}, \mathrm{e}}$ \\
\hline & K18 & $12.3 \pm 1.2^{a, b, c}$ & $20.8 \pm 7.0^{b, c, d, e}$ & $66.6 \pm 6.5^{\mathrm{h}, \mathrm{i}}$ \\
\hline \multirow{5}{*}{ Calves } & $\mathrm{T} 11 \mathrm{~B}$ & $10.7 \pm 3.3^{a, b, c}$ & $15.8 \pm 2.5^{\mathrm{a}, \mathrm{b}}$ & $27.9 \pm 3.6^{\mathrm{a}, \mathrm{b}}$ \\
\hline & $\mathrm{T} 1 \mathrm{C}$ & $6.7 \pm 1.3^{\mathrm{a}, \mathrm{b}}$ & $15.0 \pm 0.5^{\mathrm{a}, \mathrm{b}}$ & $37.9 \pm 8.1^{b, c, d}$ \\
\hline & $\mathrm{T} 12 \mathrm{~B}$ & $9.0 \pm 0.1^{a, b, c}$ & $12.8 \pm 0.3^{\mathrm{a}, \mathrm{b}}$ & $21.7 \pm 7.4^{\mathrm{a}}$ \\
\hline & TS1C & $24.0 \pm 16.7^{\mathrm{d}}$ & $29.0 \pm 16.4^{\mathrm{e}}$ & $48.8 \pm 10.8^{\mathrm{c}, \mathrm{d}, \mathrm{e}, \mathrm{f}}$ \\
\hline & SL5B & $12.0 \pm 2.6^{a, b, c}$ & $27.8 \pm 3.0^{\mathrm{d}, \mathrm{e}}$ & $60.1 \pm 4.1^{\mathrm{f}, \mathrm{g}, \mathrm{h}, \mathrm{i}}$ \\
\hline \multirow{2}{*}{ Piglets } & S3A & $13.9 \pm 1.5^{b, c}$ & $25.4 \pm 1.6^{\mathrm{c}, \mathrm{d}, \mathrm{e}}$ & $69.7 \pm 5.1^{\mathrm{i}}$ \\
\hline & S4B & $8.1 \pm 5.9^{a, b, c}$ & $11.5 \pm 0.6^{\mathrm{a}}$ & $39.8 \pm 8.6^{\mathrm{b}, \mathrm{c}, \mathrm{d}}$ \\
\hline
\end{tabular}

Data are expressed as \% of auto-aggregation measured after 3,6 , and $24 \mathrm{~h}$ of incubation. The values are means of triplicate measurements \pm standard deviation. $\mathrm{a}, \mathrm{b}, \mathrm{c}, \mathrm{d}, \mathrm{e}, \mathrm{f}, \mathrm{f}, \mathrm{g}, \mathrm{h}, \mathrm{i}$ Data in columns with different superscripts differ $(p<0.05)$.

\section{Conclusions}

To discover novel potential probiotic strains for use in humans as well as in domestic animals, we isolated a number of strains of human and animal origins, focusing on lactobacilli and bifidobacteria. All the tested strains exerted substantial adhesion capacity on human colon adenocarcinoma cell lines; the best adhesion capacity was found in the L. reuteri strain $\mathrm{K} 7$ isolated from colostrum and infant feces. All the isolates showed high auto-aggregation capacity; however, strain-specific differences were observed. Such differences were even more obvious in cell surface hydrophobicity values, which varied substantially even in the same taxonomic group. The link between cell surface hydrophobicity and adhesion capacity of the tested strains could not be demonstrated. Instead, correlation between auto-aggregation and adhesion capacity can be assumed from our findings. The strain L. reuteri K7 can be considered the best potential probiotic strain based on its properties; it showed high auto-aggregation (65.4\%), hydrophobicity (30.6\%), and good adhesion capacity to the mixed cell culture 
simulating intestinal mucosa (37.2\%). Further, the S3A strain of B. pseudolongum is of interest, as it has good adhesion capacity (29.5\%), auto-aggregation (69.7\%), and hydrophobicity (63.4\%). Among the remaining isolates, the strains from infant feces E3M2 and E2MD (both L. reuteri) are worth further testing and characterizing to evaluate other important probiotic properties they have to meet, such as their functional properties (antimicrobial activity, survival of gastrointestinal tract conditions), technological properties (viability during storage), resistance to antibiotics, etc. Future studies will elucidate the probiotic potential of these newly isolated strains.

Author Contributions: Formal analysis, G.K.; Investigation, I.H. (Iveta Hynstova) and G.K.; Methodology, I.H. (Iveta Hynstova) and I.H. (Ivana Hyrslova); Project Administration, G.K.; Resources, G.K.; Supervision, G.K.; Writing-original draft, G.K., I.H. (Iveta Hynstova), and I.H. (Ivana Hyrslova); Writing-review and editing, G.K.

Funding: This study was supported by the Ministry of Agriculture of the Czech Republic (Institutional support no. MZE-RO1419).

Conflicts of Interest: The authors declare no conflict of interest.

\section{References}

1. Hill, C.; Guarner, F.; Reid, G.; Gibson, G.R.; Merenstein, D.; Pot, B.; Morelli, L.; Canani, R.B.; Flint, H.J.; Salminen, S.; et al. The International Scientific Association for Probiotics and Prebiotics consensus statement on the scope and appropriate use of the term probiotics. Nat. Rev. Gastroenterol. Hepatol. 2014, 11, 506-514. [CrossRef] [PubMed]

2. Reid, G.; Gadir, A.A.; Dhir, R. Probiotics: Reiterating what they are and what they are not. Front. Microbiol. 2019, 10, 424. [CrossRef] [PubMed]

3. Ouwehand, A.C.; Salminen, S.; Isolauri, E. Probiotics: An overview of beneficial effects. Lact. Acid Bact. 2002, 82, 279-289.

4. Ranadheera, C.S.; Vidanarachchi, J.K.; Rocha, R.S.; Cruz, A.G.; Ajlouni, S. Probiotic delivery through fermentation: Dairy vs. non-dairy beverages. Fermentation 2017, 3, 67. [CrossRef]

5. Falah, F.; Vasiee, A.; Behbahani, B.A.; Xazdi, F.T.; Moradi, S.; Mortazavi, S.A.; Roshanak, S. Evaluation of adherence and anti-infective properties of probiotic Lactobacillus fermentum strain 4-17 against Escherichia coli causing urinary tract infection in humans. Microb. Pathog. 2019, 131, 246-253. [CrossRef] [PubMed]

6. Okochi, M.; Sugita, T.; Asai, Y.; Tanaka, M.; Honda, H. Screening of peptides associated with adhesion and aggregation of Lactobacillus rhamnosus GG in vitro. Biochem. Eng. J. 2017, 128, 178-185. [CrossRef]

7. Zuo, F.; Yu, R.; Feng, X.; Chen, L.; Zeng, Z.; Khaskheli, G.B.; Ma, H.; Chen, S. Characterization and in vitro properties of potential probiotic Bifidobacterium strains isolated from breast-fed infant feces. Ann. Microbiol. 2016, 66, 1027-1037. [CrossRef]

8. Andriantsoanirina, V.; Teolis, A.C.; Xin, L.X.; Butel, M.J.; Aires, J. Bifidobacterium longum and Bifidobacterium breve isolates from preterm and full term neonates: Comparison of cell surface properties. Anaerobe 2014, 28, 212-215. [CrossRef]

9. Behbahani, B.A.; Noshad, M.; Falah, F. Inhibition of Escherichia coli adhesion to human intestinal Caco-2 cells by probiotic candidate Lactobacillus plantarum strain L15. Microb. Pathog. 2019, 136, 103677. [CrossRef]

10. Davoodabadi, A.; Dallal, M.M.S.; Foroushani, A.R.; Douraghi, M.; Harati, F.A. Antibacterial activity of Lactobacillus spp. isolated from the feces of healthy infants against enteropathogenic bacteria. Anaerobe 2015, 34, 53-58.

11. García-Cayuela, T.; Korany, A.M.; Bustos, I.; de Cadinanos, L.P.G.; Requena, T.; Peláez, C.; Martínez-Cuesta, M.C. Adhesion abilities of dairy Lactobacillus plantarum strains showing an aggregation phenotype. Food Res. Int. 2014, 57, 44-50. [CrossRef]

12. Monteagudo-Mera, A.; Rastall, R.A.; Gibson, G.R.; Charalampopoulos, D.; Chatzifragkou, A. Adhesion mechanisms mediated by probiotics and prebiotics and their potential impact on human health. Appl. Microbiol. Biotechnol. 2019, 103, 6463-6472. [CrossRef] [PubMed]

13. Chaffanel, F.; Charron-Bourgoin, F.; Soligot, C.; Kebouchi, M.; Bertin, S.; Payot, S.; Le Roux, Y.; Leblond-Bourget, N. Surface proteins involved in the adhesion of Streptococcus salivarius to human intestinal epithelial cells. Appl. Microbiol. Cell Physiol. 2018, 102, 2851-2865. [CrossRef] [PubMed] 
14. Lesuffleur, T.; Barbat, A.; Dussaulx, E.; Zweibaum, A. Growth adaptation to methotrexate of HT-29 human colon-carcinoma cells is associated with their ability to differentiate into columnar absorptive and mucus-secreting cells. Cancer Res. 1990, 50, 6334-6343.

15. Haddaji, N.; Mahdhi, A.K.; Krifi, B.; Ismail, M.B.; Bakhrouf, A. Change in cell surface properties of Lactobacillus casei under heat shock treatment. FEMS Microbiol. Lett. 2015, 362. [CrossRef]

16. Hospenthal, M.K.; Costa, T.R.D.; Waksman, G. A comprehensive guide to pilus biogenesis in gram-negative bacteria. Nat. Rev. Microbiol. 2017, 15, 365-379. [CrossRef]

17. Gomaa, E.Z. Antimicrobial and anti-adhesive properties of biosurfactant produced by lactobacilli isolates, biofilm formation and aggregation ability. J. Gen. Appl. Microbiol. 2013, 59, 425-436. [CrossRef]

18. Saito, K.; Tomita, S.; Nakamura, T. Aggregation of Lactobacillus brevis associated with decrease in $\mathrm{pH}$ by glucose fermentation. Biosci. Biotechnol. Biochem. 2019, 83, 1523-1529. [CrossRef]

19. De Souza, B.M.S.; Borgonovi, T.F.; Casarotti, S.N.; Todorov, S.D.; Penna, A.L.B. Lactobacillus casei and Lactobacillus fermentum strains isolated from mozzarella cheese: Probiotic potential, safety, acidifying kinetic parameters and viability under gastrointestinal tractconditions. Probiotics Antimicrob. Proteins 2018, 11, 382-396. [CrossRef]

20. Pan, M.; Kumaree, K.K.; Shah, N.P. Physiological changes of surface membrane in Lactobacillus with prebiotics. J. Food Sci. 2017, 82, 744-750. [CrossRef]

21. Vlková, E.; Salmonova, H.; Bunesova, V.; Geigerova, M.; Rada, V.; Musilova, S. A new medium containing mupirocin, acetic acid, and norfloxacin for the selective cultivation of bifidobacterial. Anaerobe 2015, 34, 27-33. [CrossRef] [PubMed]

22. Vinderola, C.; Medici, M.; Perdigon, G. Relationship between interaction sites in the gut, hydrophobicity, mucosal immunomodulating capacities and cell wall protein profiles in indigenous and exogenous bacteria. J. Appl. Microbiol. 2004, 96, 230-243. [CrossRef] [PubMed]

23. Kadlec, R.; Jakubec, M. The effect of prebiotics on adherence of probiotics. J. Dairy Sci. 2014, 97, 1983-1990. [CrossRef] [PubMed]

24. Fernandes, R. Microbiology handbook: Dairy products. R. Soc. Chem. 2009, 3, 173. [CrossRef]

25. Fernández, L.; Langa, S.; Martín, V.; Maldonado, A.; Jiménez, E.; Martín, R.; Rodríguez, J.M. The human milk microbiota: Origin and potential roles in health and disease. Pharmacol. Res. 2013, 69, 1-10. [CrossRef]

26. Chambers, J.V. The microbiology of raw milk. In Dairy Microbiology Handbook: The Mic Robiology of Milk and Milk Products; Robinson, R.K., Ed.; Wiley: Hoboken, NJ, USA, 2002; pp. 39-90.

27. Kim, J.K.; Shin, E.C.; Park, H.G. Fructooligosaccharides decreased the ability of probiotic Escherichia coli Nissle 1917 to adhere to co-cultures of human intestinal cell lines. J. Korean Soc. Appl. Biol. Chem. 2015, 58, 45-52. [CrossRef]

28. Ouwehand, A.C.; Salminen, S. In vitro adhesion assays for probiotics and their in vivo relevance: A review. Microb. Ecol. Health Dis. 2003, 15, 175-184. [CrossRef]

29. Mantzourani, I.; Chondrou, P.; Bontsidis, C.; Karolidou, K.; Terpou, A.; Alexopoulos, A.; Bezirtzoglou, E.; Galanis, A.; Plessas, S. Assessment of the probiotic potential of lactic acid bacteria isolated from kefir grains: Evaluation of adhesion and antiproliferative properties in in vitro experimental systems. Ann. Microbiol. 2019, 69, 751-763. [CrossRef]

30. Hernandez-Hernandez, O.; Muthaiyan, A.; Moreno, F.J.; Montilla, A.; Sanz, M.L.; Ricke, S.C. Effect of prebiotic carbohydrates on the growth and tolerance of Lactobacillus. Food Microbiol. 2012, 30, 355-361. [CrossRef]

31. Sidira, M.; Kourkoutas, Y.; Kanellaki, M.; Charalampopoulos, D. In vitro study on the cell adhesion ability of immobilized lactobacilli on natural supports. Food Res. Int. 2015, 76, 532-539. [CrossRef]

32. Wu, Q.; Shah, N.P. Effects of elaidic acid, a predominant industrial trans fatty acid, on bacterial growth and cell surface hydrophobicity of lactobacilli. J. Food Sci. 2014, 79, 2485-2490. [CrossRef] [PubMed]

33. Shakirova, L.; Grube, M.; Gavare, M.; Auzina, L.; Zikmanis, P. Lactobacillus acidophilus La5 and Bifidobacterium lacis $\mathrm{Bb} 12$ cell surface hydrophobicity and survival of the cells under adverse environmental conditions. J. Nutr. 2013, 40, 85-93.

34. Martienssen, M.; Reichel, O.; Kohlweyer, U. Surface properties of bacteria from different wastewater treatment plants. Acta Biotechnol. 2001, 21, 207-225. [CrossRef]

35. Kos, B.; Suskovic, J.; Vukovic, S.; Simpraga, M.; Frece, J.; Matosic, S. Adhesion and aggregation ability of probiotic strain Lactobacillus acidophillus M92. J. Appl. Microbiol. 2003, 94, 981-987. [CrossRef] 
36. Sorroche, F.G.; Spesia, M.B.; Zorreguieta, A.; Giordano, W. A positive correlation between bacterial autoaggregation and biofilm formation in native Sinorhizobium meliloti isolates from Argentina. Appl. Environ. Microbiol. 2012, 78, 4092-4101. [CrossRef]

37. Collado, M.C.; Meriluoto, J.; Salminen, S. Adhesion and aggregation properties of probiotic and pathogen strains. Eur. Food Res. Technol. 2008, 226, 1065-1073. [CrossRef]

38. Mohanty, D.; Panda, S.; Kumar, S.; Ray, P. In vitro evaluation of adherence and anti-infective property of probiotic Lactobacillus plantarum DM 69 against Salmonella enterica. Microb. Pathog. 2019, 126, 212-217. [CrossRef]

39. Todorov, S.D.; Dicks, L.M.T. Evaluation of lactic acid bacteria from kefir, molasses and olive brine as possible probiotics based on physiological properties. Ann. Microbiol. 2008, 58, 661-670. [CrossRef]

40. Pisano, M.B.; Casula, M.; Corda, A.; Fadda, M.E.; Deplano, M.; Cosentino, S. In vitro probiotic characteristics of Lactobacillus strains isolated from Fiore Sardo cheese. Ital. J. Food Sci. 2008, 20, 505-516.

41. Mackenzie, D.A.; Jeffers, F.; Parker, M.L.; Vibert-Vallet, A.; Bongaerts, R.J.; Roos, S.; Walter, J.; Juge, N. Strain-specific diversity of mucus-binding proteins in the adhesion and aggregation properties of Lactobacillus reuteri. Microbiology 2010, 156, 3368-3378. [CrossRef]

(C) 2019 by the authors. Licensee MDPI, Basel, Switzerland. This article is an open access article distributed under the terms and conditions of the Creative Commons Attribution (CC BY) license (http://creativecommons.org/licenses/by/4.0/). 